\title{
Association between aflatoxin B1 occupational airway exposure and risk of hepatocellular carcinoma: a case-control study
}

\author{
Hao Lai • Xianwei Mo • Yang Yang • Ke He • Jun Xiao • \\ Chao Liu • Jiansi Chen • Yuan Lin
}

Received: 9 May 2014 / Accepted: 11 June 2014 / Published online: 25 June 2014

(C) The Author(s) 2014. This article is published with open access at Springerlink.com

\begin{abstract}
The aim of this study was to determine the airway exposure of sugar and papermaking factory workers to aflatoxin $\mathrm{B} 1$ (AFB1) and to explore the potential association between AFB1 airway exposure and the risk of hepatocellular carcinoma (HCC) in a case-control study. Dust samples were collected from the sugarcane bagasse warehouse, and presser and paper production workshops. Blood samples were collected from 181 workshop employees and 203 controls who worked outside the workshop. AFB1 albumin adducts were detected using a double antibody sandwich enzyme-linked immunosorbent assay (ELISA). To explore the association between AFB1 airway exposure and the risk of HCC, the medical records of $68 \mathrm{HCC}$ patients who worked in a sugar and papermaking factory between January 1994 and December 2013 were analyzed. A questionnaire was used to collect information from 150 healthy controls who worked for the same company and lived near the factory. AFB1 was detected in the dust samples, but could not be detected in any of the rice samples. An analysis of serum samples revealed serum AFB1 albumin adducts in $102(56.35 \%)$ of the study participants. However, in the control group, only 12 (5.9\%) individuals had detectable levels of AFB1 albumin adducts. Those with airway exposure to Aspergillus flavuscontaminated dust had an elevated risk of HCC compared to those without exposure (odds ratio, 5.24; $95 \%$ confidence interval, 2.77-9.88; $P=0.00$ ). The findings of this study
\end{abstract}

H. Lai $\cdot$ X. Mo $\cdot$ Y. Yang $\cdot$ J. Xiao $\cdot$ C. Liu $\cdot$ J. Chen $\cdot$ Y. Lin $(\bowtie)$ Department of Gastrointestinal Surgery, Affiliated Cancer Hospital of Guangxi Medical University, 71 Hedi Road,

Nanning 530021, Guangxi Autonomous Region, China

e-mail: doctoryuanlin@sina.cn

\section{K. He}

Department of Head and Neck Surgery, Affiliated Cancer Hospital of Guangxi Medical University, Nanning 530021, Guangxi

Autonomous Region, China indicate that occupational AFB1 airway exposure might be associated with the risk of AFB1-related HCC among the population that was used in this study. Intervention programs aimed at reducing exposure to inhalational AFB1 are needed urgently. Additional suitably designed, multicenter, prospective studies using large samples are needed to further confirm the results.

Keywords Hepatocellular carcinoma · Aflatoxin B1 · Airway exposure $\cdot$ Case-control study

\section{Introduction}

Hepatocellular carcinoma (HCC) is the fifth most common human cancer, with approximately 750,000 new cases occurring worldwide each year [1]. Eighty percent of global HCCs occur in developing countries [2], including the People's Republic of China [3]. Chronic hepatitis B virus (HBV) infection and exposure to aflatoxin B1 (AFB1) are the principal causes of HCC in China and in other regions of the world [4].

Aflatoxins (AFB1, AFB2, AFG1, and AFG2) are known to be carcinogenic to both humans and animals, with AFB1 being the most potent hepatotoxic and hepatocarcinogenic agent [4]. The principal source of AFB1 exposure is consumption of various food products, particularly cereals, oleaginous seeds, cocoa, coffee, grapevine, wine, fruits, spices, and dried fruit [5]. Numerous studies have demonstrated that a linear correlation exists between serum AFB1 dietary exposure and the risk of HCC [6-10]. In recent years, primary prevention strategies against AFB1 dietary exposure and the HBV, which are the other two principal etiological risk factors in HCC, have offered hope of lowering HCC rates in China [11]. Examples of strategies include HBV vaccination of infants and food safety procedures to control AFB1 contamination 
[11]. However, the incidence of HCC remains high [2]. According to our clinical observations, the prevalence is particularly elevated in specific populations, such as papermill and sugar factory workers. The dietary habits and HBV infective rate of these workers are similar to those of the rest of the population. Thus, we considered whether another AFB1 exposure route might contribute to HCC in these workers.

Inhalation of contaminated airborne dust is an additional route of exposure that researchers have largely ignored. Airborne aflatoxin was previously detected in dust samples during the handling of contaminated corn [12], and the agricultural workers were directly exposed to the airborne aflatoxin in grain dust through inhalation [5].

Numerous studies that include a focus on China and other countries have established a strong association between AFB1 dietary exposure and the risk of HCC [13-16]. However, only a small number of studies have included an examination of airway exposure to AFB1 [5, 17-19], and the role that inhaled AFB1 plays as an occupational risk factor in the development of HCC is largely unknown. The aim of this study was to determine the AFB1 airway exposure in sugar and papermaking factory workers and to explore the association between AFB1 airway exposure and HCC in this population by employing a case-control study.

\section{Materials and methods}

The Research Ethics Committee of the Affiliated Cancer Hospital of Guangxi Medical University approved this study. This study was conducted between October 2013 and March 2014 in a sugar and papermaking factory located in the Guangxi Autonomous Region of China. It is the largest sugar factory in Guangxi. The principal operations conducted in this factory are sugar production and papermaking using sugarcane, which a previous study demonstrated is a potential source of fungal growth [20]. The workers' airways were directly exposed to the AFB1-contaminated dust when producing sugar and paper. They did not always use respiratory protection or other types of protective devices at work (Fig. 1).

\section{Part I: determination of AFB1 airway exposure}

\section{Dust sample collection}

Dust samples were collected from the sugarcane bagasse warehouse (Fig. 2) and presser (Fig. 3) and paper production workshops of the mentioned factory because these were regarded as the most likely sites of contamination. AFB1 was isolated from the dust samples using the method described by Autrup et al. [17]. Dust samples $(0.9 \mathrm{mg})$ were suspended in $5 \mathrm{ml}$ of $80 \%$ methanol, and $0.1 \mathrm{mg}$ of sodium chloride was added to the turbid liquid. After $30 \mathrm{~min}$, these

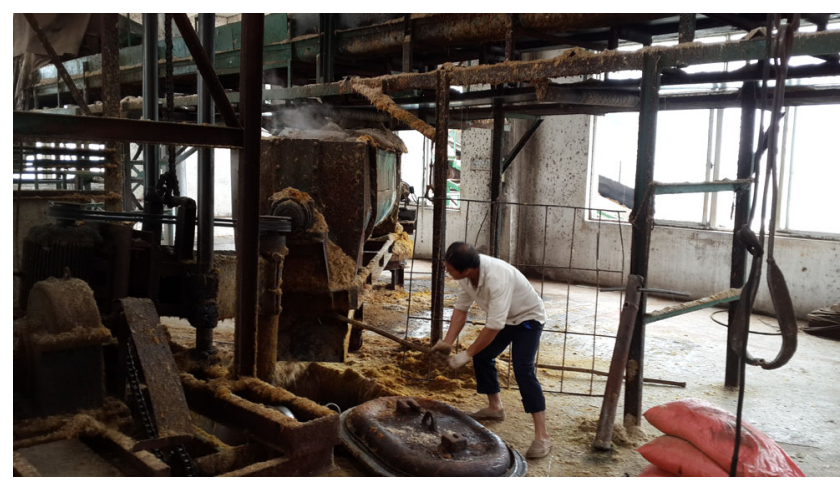

Fig. 1 A sugar factory worker who did not use respiratory protection or other type of protective device at work

extracts were centrifuged for $20 \mathrm{~min}$, and the supernatants were collected. This procedure was repeated three times, and all the supernatants were pooled. The extract $(3 \mathrm{ml})$ was adjusted using $10 \%$ methanol, and $10 \mathrm{ml}$ of this solution were loaded into aflatoxin test affinity column. After washing with distilled water, the AFB1 were eluted using $100 \%$ methanol.

\section{Detection of AFB1 in dust samples from the sugar and papermaking factory}

The concentration of AFB1 in the dust samples was analyzed using an indirect competitive enzyme linked immunosorbent assay (ELISA) (Reagen, USA). ELISA wells were coated using $100 \mathrm{ng} / \mathrm{ml}$ of AFB1 of bovine serum albumin (BSA) in a sodium carbonate buffer with $\mathrm{pH} 9.6(150 \mathrm{ml} / \mathrm{well})$ and left overnight at $4{ }^{\circ} \mathrm{C}$. A phosphate-buffered saline was used to wash the ELISA plates, and BSA was added to the plates and allowed to stand at $37^{\circ} \mathrm{C}$ for $1 \mathrm{~h}$. Phosphate-buffered saline containing $0.05 \%$ Tween (PBST) was used to wash the ELISA plates again, and $100 \mathrm{ml}$ of AFB1 standards ranging from $25 \mathrm{ng} / \mathrm{ml}$ to $10 \mathrm{pg} / \mathrm{ml}$ was then added to the plates. Preincubation was conducted using $50 \mathrm{ml}$ of antiserum diluted in PBST-BSA $(1: 6,000)$, and maintained for $45 \mathrm{~min}$ at $37^{\circ} \mathrm{C}$. The extraction solution from the dust samples and aqueous methanol- $\mathrm{KCl}$ were added to wells at 1:10 dilution in PBST-

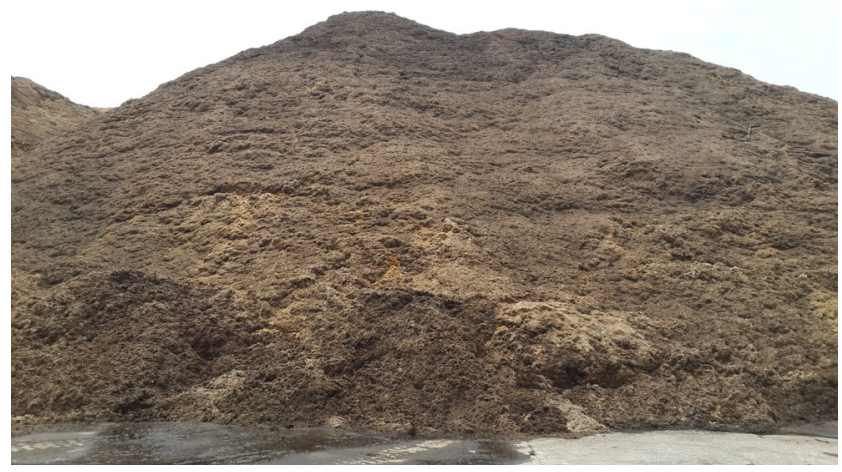

Fig. 2 Dust sample in sugarcane bagasse warehouse 


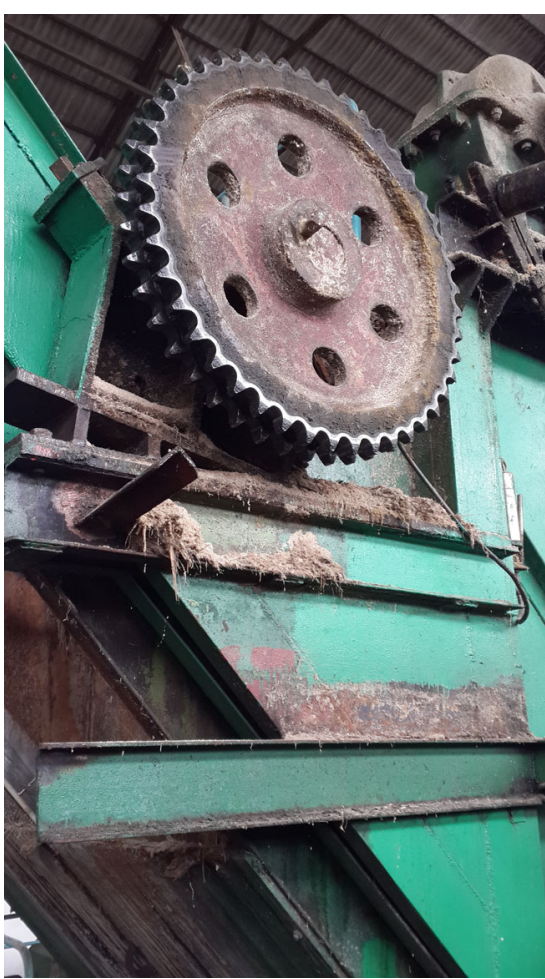

Fig. 3 Dust sample in the presser workshop

BSA. Goat anti-rabbit immunoglobulins conjugated to alkaline phosphatase were used at a 1:4,000 dilution to detect rabbit antibodies that were attached to AFB1-BSA. $S$ Nitrophenyl phosphate $(0.5 \mathrm{mg} / \mathrm{ml})$ was used as a substrate. Absorbance was recorded at $450 \mathrm{~nm}$ using an ELISA plate reader (Biorad-680, USA) after incubation at $28^{\circ} \mathrm{C}$ for $45 \mathrm{~min}$ to $1 \mathrm{~h}$ in the dark. Standard curves were obtained by plotting $\log _{10}$ values of AFB1 dilutions at A450. The AFB1 (ng/ml) in the samples was determined by referring to standard curves: AFB $1 \mathrm{mg} / \mathrm{kg}$ of dust sample $=$ aflatoxin $(\mathrm{ng} / \mathrm{ml})$ in sample $\times$ buffer $(\mathrm{ml}) \times$ extraction solvent $(\mathrm{ml}) /$ sample weight $(\mathrm{g})$. To test the recovery of AFB1, $20 \mathrm{~g}$ of dust was mixed using pure AFB1 (Sigma, St. Louis, MO, USA) to produce concentrations ranging from 5 to $100 \mathrm{mg} / \mathrm{kg}$.

\section{Dietary AFB1 analysis}

Fifty rice samples were collected randomly from the participants and from the kitchen in the factory. AFB1 was analyzed through an indirect competitive ELISA using the process that was described earlier.

\section{Selection of the study subjects and blood sample collection}

Employees were enrolled in the study group if they met the following criteria: (1) they have worked in the sugarcane bagasse warehouse and presser or paper production workshops for at least 4 weeks; (2) they had not eaten any moldy foods within 3 months; and (3) they had not been working for any other agribusiness in the 3 months prior to the start of this study. We excluded participants from the study group if they met any of the following criteria: (1) they did not work in the mentioned workshops; (2) they had eaten moldy food once within 3 months; and (3) they had worked in any other agribusiness in the 3 months prior to the start of this study.

We selected participants for the control group if they met the following criteria: (1) they worked for the sugar mill or papermaking factory and in positions outside of it, such as administrative work in an office or as workers in a store nearby; (2) they had not eaten any moldy foods within 3 months; and (3) they had not been working in any other agribusiness in the 3 months prior to the start of this study. We excluded participants if they met any of the following criteria: (1) they had directly inhaled the dust while working for the mentioned company once within 3 months; (2) they had eaten moldy food once within 3 months; and (3) they had worked in any other agribusiness activity in the 3 months prior to the start of this study.

At least 181 workshop employees and 203 controls were enrolled in this study. Blood samples $(5 \mathrm{ml})$ were collected from these study participants, and serum was isolated from the blood samples by centrifugation and stored at $-20{ }^{\circ} \mathrm{C}$ until further analysis.

\section{Determination of serum AFB1 albumin adducts level}

A double antibody sandwich ELISA for humans was used to detect serum AFB1 albumin adducts. The sensitivity of the analysis using ELISA was $6 \mathrm{pg} / \mathrm{mg}$ albumin (Yisen, Shanghai, China). Serum samples were thawed for $1 \mathrm{~h}$ before conducting the ELISA analysis. Standards were diluted according to the manufacturer's instruction. A total of $10 \mu \mathrm{l}$ of the test sample was diluted using $40 \mu \mathrm{l}$ sample diluent. A reagent was not added to the blank control. After closing the plate using a closure plate membrane, the plates were incubated at $37^{\circ} \mathrm{C}$ for $30 \mathrm{~min}$. The closure plate membrane was then opened and the liquid in each well was discarded and swung, taking care not to leave any liquids in each well. A wash buffer was added to the wells. After $30 \mathrm{~s}$, the plate was inverted, and residual liquid was tapped out. This step was repeated five times. Subsequently, $50 \mu \mathrm{l}$ of EIA kit was added to the test well again. The plates were incubated and washed again, as previously described.

In the next step, $50 \mu \mathrm{l}$ of chromogenic agent $A$ and $50 \mu \mathrm{l}$ of chromogenic agent $\mathrm{B}$ were added to each well in turn, and the plate was kept in the dark for $30 \mathrm{~min}$ at $37^{\circ} \mathrm{C}$. Subsequently, $50 \mu \mathrm{l}$ of stopping solution was added to the wells, thus changing the color of the liquid to yellow. The absorption was read at $450 \mathrm{~nm}$. 
Part II: assessment of AFB1 airway exposure and risk of HCC

\section{Study population}

To evaluate AFB1 inhalation and the risk of HCC, a casecontrol study was conducted, which comprised 68 HCC patients who worked at the sugar mill and papermaking factory between January 1994 and December 2013, and 150 healthy controls who worked for the same company during the same period. The records of the HCC patients were obtained from community and governmental hospitals, whereas the control group participants were selected from the mentioned company using a random sampling method. The study participants were excluded from the control group if they met any of the following criteria: (1) they had been working for their company for less than 5 years; and (2) they did not reside at the same residence. A questionnaire was used to collect information on the gender, HBV infection status, alcohol intake, smoking status, moldy food intake, and occupational airway exposure to dust of the controls. We were unable to compare the serum AFB1 albumin adduct levels of the cases and controls because the information on the HCC patients was obtained by conducting a retrospective analysis, most of the patients had died, and serum samples that had been collected when they were alive were impossible to obtain.

\section{Statistical analysis}

In Part I, an independent samples $t$ test was performed to evaluate whether the serum AFB1 albumin adduct levels of the workshop workers and controls were statistically significantly different. A one-way analysis of variance was performed to evaluate whether the concentration of AFB1 in dust samples, which were collected from the sugarcane bagasse warehouse and the presser and paper production workshops were significantly different. A chi-square test was also used to assess whether the characteristics of the participants in the two groups were different. In Part II, Fisher's exact test or a chi-square test, whichever was appropriate, were used to examine the differences between the cases and the controls. The odds ratio (OR) and $95 \%$ confidence intervals $(95 \% \mathrm{CI})$ for HCC risk were calculated using an unconditional logistic regression, and a full assessment of potential confounding factors was conducted. Statistical analysis was performed using the Statistical Package for the Social Science, version 16.0 (SPSS 16.0), and a $P$ value $<0.05$ was considered statistically significant.

\section{Results}

Fifteen dust samples were collected from the workshop (sugarcane bagasse warehouse, and the presser and paper production workshops). The concentration of AFB1 in dust samples, which were collected from the sugarcane bagasse warehouse and the presser and paper production workshops, were $7.2 \pm 1.30,8.0 \pm 1.23$ and $8.6 \pm 1.82 \mu \mathrm{g} \mathrm{kg}^{-1}$, respectively (Table 1). The concentration of AFB1 in the dust samples was not statistically significant in these sites $(P=0.35)$. AFB1 was not detected in any of the rice samples.

The demographic data are listed in Table 2. A statistically significant difference was not detected for the age, gender, body mass index (BMI), daily work periods, HBV infection, and moldy food intake of the two groups. However, the difference in the serum AFB1 albumin adduct levels of the workshop workers and the controls was statistically significant. Serum AFB1 albumin adducts were detected in 102 (56.35\%) workshop employees, with values ranging from 8 to $212 \mathrm{pg} / \mathrm{mg}$ albumin (mean value $38.51 \pm 44.80 \mathrm{pg} / \mathrm{mg}$ albumin). In contrast, only 12 (5.9\%) controls had detectable levels of AFB1 albumin adducts, with values ranging from 8 to $26 \mathrm{pg} / \mathrm{mg}$ albumin (mean value $15.58 \pm 6.42 \mathrm{pg} / \mathrm{mg}$ albumin).

Table 3 shows the results of a comparative analysis of the risk of $\mathrm{HCC}$ with the principal etiological factors in the cases and controls. We found that the risk of HCC was associated with exposure to airborne dust (OR, 5.24; 95 \% CI, 2.77-9.88; $P=0.00)$ and $\mathrm{HBV}$ infection (OR, 4.46; $95 \% \mathrm{CI}, 2.02-9.85$; $P=0.00)$. However, no statistically significant risk was observed with respect to gender (OR, 1.20; $95 \%$ CI, 0.67-2.16; $P=0.54$ ), alcohol intake (OR, 0.88; $95 \% \mathrm{CI}, 0.50-1.56 ; P=$ 0.66), smoking status (OR, 0.87; $95 \% \mathrm{CI}, 0.49-1.56 ; P=$ $0.64)$, and family history of $\mathrm{HCC}(\mathrm{OR}, 1.72 ; 95 \% \mathrm{CI}, 0.57-$ 5.16; $P=0.33)$.

\section{Discussion}

$\mathrm{HCC}$ is one of the principal cancer types that affects the people living in the Guangxi Zhuang Autonomous Region, where most disease occurs due to environmental exposure to AFB1 [8-10]. AFB1 exposure occurs predominantly through the food chain, but inhalation is an additional route of exposure. Airborne exposure to AFB1 principally occurs in workers who are in contact with Aspergillus flavus-contaminated dust $[5,17,21]$. The strong association between AFB1 dietary

Table 1 Concentration of AFB1 in dust samples from different workshop

Workshop

Concentration of AFB1 in dust samples

Sugarcane bagasse warehouse

$7.2 \pm 1.30 \mu \mathrm{g} \mathrm{kg}^{-1}$

Presser workshop

$8.0 \pm 1.23 \mu \mathrm{g} \mathrm{kg}^{-1}$

Paper production workshop

$P$ value

$8.6 \pm 1.82 \mu \mathrm{g} \mathrm{kg}^{-1}$

0.35 
Table 2 Characteristics of the involved participators

\begin{tabular}{llll}
\hline Information & Workshop workers $(n=181)$ & Controls $(n=203)$ & $P$ value \\
\hline Age (years) & $40.38 \pm 9.32$ & $38.13 \pm 9.98$ & 0.12 \\
Gender (male/female) & $127 / 54$ & $139 / 64$ & 0.72 \\
BMI & $22.22 \pm 2.84$ & $22.56 \pm 2.84$ & 0.64 \\
Daily work periods (h) & $7.89 \pm 0.78$ & $7.85 \pm 0.56$ & 0.63 \\
HBV infection & & & 0.51 \\
$\quad$ Positive & 16 & 22 & \\
$\quad 165$ & 181 & \\
Mogative & & & 0.00 \\
$\quad$ Yes & & & 0.00 \\
$\quad$ No & $38.51 \pm 44.80 \mathrm{pg} / \mathrm{mg}$ albumin & $15.58 \pm 6.42 \mathrm{pg} / \mathrm{mg}$ albumin \\
Serum AFB1 albumin adducts & 102 & 12 & \\
Positive & 79 & 191 & \\
Negative & & &
\end{tabular}

exposure and the risk of HCC has been established [4]. However, the association between airway exposure to AFB1 and the risk of HCC is largely unknown, and studies in this field are apparently nonexistent. The present study showed that AFB1 airway exposure might result in positive serum AFB1 adducts and be associated with a risk of HCC.

Numerous studies have revealed that poultry production and rice mill workers who are indirect contact with grain dust are often exposed to AFB1 [5, 17, 18, 21, 22]. This study demonstrated that sugar refinery workers are also at risk of inhalational exposure to AFB1. The sugarcane plant
(Saccharum officinarum) is the predominant crop used in sugar production in the province of Guangxi. The sugar present in the stem of $S$. officinarum is the principal source of fungal growth [20]. The sugar factory workers in this study might constitute a high-risk population due to the absence of precautions against $A$. flavus in this factory. Based on a conservative estimation, the temperature in the factory workshop was $35-40^{\circ} \mathrm{C}$. Due to the factory's high temperature, the workers were reluctant to use respiratory protection or other types of protective devices. They also seemed to have no knowledge about the need for protection.
Table 3 Demographic characteristics of $\mathrm{HCC}$ cases and controls

$H B V$ hepatic B vivus, $H C C$ hepatocellular carcinoma, $O R$ odds ratio

\begin{tabular}{|c|c|c|c|c|}
\hline Variables & $\begin{array}{l}\text { HCC cases } \\
(n=68)\end{array}$ & $\begin{array}{l}\text { Controls } \\
(n=150)\end{array}$ & OR $(95 \% \mathrm{CI})$ & $P$ value \\
\hline \multicolumn{5}{|l|}{ Gender } \\
\hline Male & 42 & 86 & $1.20(0.67-2.16)$ & 0.54 \\
\hline Female & 26 & 64 & & \\
\hline \multicolumn{5}{|c|}{ Alcohol intake } \\
\hline Yes & 35 & 82 & $0.88(0.50-1.56)$ & 0.66 \\
\hline No & 33 & 68 & & \\
\hline \multicolumn{5}{|c|}{ Smoking status } \\
\hline Yes & 39 & 91 & $0.87(0.49-1.56)$ & 0.64 \\
\hline No & 29 & 59 & & \\
\hline \multicolumn{5}{|c|}{ HBV infection } \\
\hline Positive & 19 & 12 & $4.46(2.02-9.85)$ & 0.00 \\
\hline Negative & 49 & 138 & & \\
\hline \multicolumn{5}{|c|}{ Family history of HCC } \\
\hline Yes & 6 & 8 & $1.72(0.57-5.16)$ & 0.33 \\
\hline No & 62 & 142 & & \\
\hline \multicolumn{5}{|c|}{ Exposure to airborne dust } \\
\hline Yes & 50 & 52 & $5.24(2.77-9.88)$ & 0.00 \\
\hline No & 18 & 98 & & \\
\hline
\end{tabular}


Pulmonary exposure to AFB1-laden dust at work is common, and most studies of AFB1 airway exposure have focused on its carcinogenic effect on the lung and its related mechanisms [23-26]. The carcinogenic effect of AFB1 airway exposure on other organs has not been studied. The detection of serum AFB1 albumin adducts in the current study suggests that the liver might be a potential target for airway exposure to AFB1. In the study, 102 of the 181 workshop employees (56.35\%) who were directly exposed to A. flavus-contaminated dust had detectable levels of serum AFB1, with values ranging from 8 to $212 \mathrm{pg} / \mathrm{ml}$. This finding is consistent with the results of previous studies [5, 17], which reported positive serum AFB1 albumin adducts among workshop workers who had been directly exposed to grain dust. In the current study, 12 controls had detectable levels of serum AFB1 albumin adducts. This might be attributed to experimental error. The absence of detectable levels of serum AFB1 albumin adducts in some of the workshop workers might be caused by individual differences or different concentrations of dust in some areas.

Serum AFB1 albumin adducts are of substantial interest because they reflect damage to critical molecular targets and damage to the absorption, distribution, and metabolism of AFB1 biotransformation in vivo [27]. Although AFB1 is harmless, members of the cytochrome P450 family convert the innocuous parent molecule of AFB1 into mutagenic and carcinogenic intermediates. AFB1 is converted into AFB18,9-exo-epoxide, which, in turn, is converted into the 8,9dihydroxy-8- $\left(N^{7}\right)$ guanyl-9-hydroxy AFB1 adduct [4].

To date, all animal models that have been exposed to AFB1 have developed HCC [4]. Numerous studies found a doseresponse relationship between levels of AFB1 adducts, the risk of HCC, and the number of years of exposure toAFB1, as measured by years living in a high AFB1 exposure region [6, $8-10]$. The findings of this study are consistent with studies that found that AFB1 airway exposure was associated with positive serum AFB1 adducts, which might be correlated with an increased risk of AFB1-related HCC. As shown in Table 3, both airborne dust exposure and HBV infection contributed to the development of HCC, but the airborne dust exposure played a greater role than HBV infection, which is a leading public health and social problem in China and is associated with the development of HCC [28]. In this study, the difference in levels of detectable AFB1 adducts between the workshop workers and the controls was statistically significant, and the HBV infection rate between them was similar. Thus, we conclude that AFB1 airway exposure was the principal cause of the HCC in this study.

Although the AFB1 DNA adducts have greater relevance in relation to HCC [29], we used AFB1 albumin adducts to assess AFB1 exposure. One of the advantages of AFB1 albumin adducts is that their half-time ranges between 2 and 3 weeks [30]. In contrast, the half-time of AFB1 is nearly
30 min and that of AFB1 DNA adducts in animals is less than $24 \mathrm{~h}$. Additionally, measurements of albumin adducts are particularly useful because they require simple, facile immunoassays that can be applied to large numbers of samples in field studies [31]. A previous animal study reported a substantial correlation between the binding of AFB1 to serum albumin and liver DNA [32]. The same study showed that that binding to serum albumin was a good biomarker of binding to target cell DNA, even at different doses of AFB1 [17].

In summary, the results of the current study suggest that sugar and papermaking factory workers were exposed inhalationally to AFB1 and that this exposure might be associated with the development of HCC in this population. Therefore, intervention programs are needed urgently. First, because the temperature in workshop is elevated and workers are reluctant to use respiratory protection, suitably planned exhaust systems should be installed to decrease the temperature in the workshops. Second, the workers should be advised to wear protective masks when they work. Third, the company should reduce the level of AFB1 in the raw material (S. officinarum) because it is the principal source of fungal growth. Fourth, a chemoprevention program involving an intervention that employs green tea should be conducted among workshop workers because numerous studies have indicated that green tea could effectively modulate the AFB1 metabolism and metabolic activation [33], and inhibit the initiation and promotion steps of AFB1 hepatocarcinogenesis [34].

This study has numerous limitations. First, the association between AFB1 airway exposure and the risk of HCC was assessed in a small number of individuals in a single center using retrospective data. Second, the number of HCC cases in each year was small. Third, we could not determine the AFB1 adduct level in the HCC patients because most of them had died. Therefore, suitably designed, multicenter, prospective studies with large samples should be conducted to assess airway exposure to AFB1 and the risk of HCC. Fourth, potential bias might be produced because we used random sampling to determine the AFB1 contamination of the dust samples. Lastly, uncontrolled or unmeasured confounding factors, such as the effects of other environmental factors or gene polymorphisms, which also potentially produce biases, might have affected the incidence of HCC.

\section{Conclusions}

The findings of this study indicate that occupational AFB1 airway exposure might be associated with the risk of AFB1related HCC among the population that was used in this study. Intervention programs aimed at reducing exposure to inhalational AFB1 are needed urgently. Additional suitably 
designed, multicenter, prospective studies using large samples are needed to further confirm the results.

Acknowledgments This study was funded by the Guangxi Natural Science Fund (No. 2011GXNSFA018300).

\section{Conflicts of interest None}

Open Access This article is distributed under the terms of the Creative Commons Attribution License which permits any use, distribution, and reproduction in any medium, provided the original author(s) and the source are credited.

\section{References}

1. Ferlay J, Shin HR, Bray F, Forman D, Mathers C, Parkin DM. Estimates of worldwide burden of cancer in 2008: GLOBOCAN 2008. Int J Cancer. 2010;127:2893-917.

2. Kew MC. Hepatocellular carcinoma in developing countries: prevention, diagnosis and treatment. World J Hepatol. 2012;4:99-104.

3. Qi LN, Li LQ, Chen YY, Chen ZH, Bai T, Xiang BD, et al. Genomewide and differential proteomic analysis of hepatitis $\mathrm{B}$ virus and aflatoxin B1 related hepatocellular carcinoma in Guangxi, China. PLoS One. 2013;8:e83465.

4. Kew MC. Aflatoxins as a cause of hepatocellular carcinoma. J Gastrointest Liver Dis. 2013;22:305-10.

5. Viegas S, Veiga L, Malta-Vacas J, Sabino R, Figueredo P, Almeida A, et al. Occupational exposure to aflatoxin $(\mathrm{AFB}(1))$ in poultry production. J Toxicol Environ Health A. 2012;75:1330-40.

6. Long XD, Yao JG, Huang YZ, Huang XY, Ban FZ, Yao LM, et al. DNA repair gene XRCC7 polymorphisms (rs\#7003908 and rs\#10109984) and hepatocellular carcinoma related to AFB1 exposure among Guangxi population, China. Hepatol Res. 2011;41:108593.

7. Xu L, Qian G, Tang L, Su J, Wang JS. Genetic variations of hepatitis $B$ virus and serum aflatoxin-lysine adduct on high risk of hepatocellular carcinoma in southern Guangxi, China. J Hepatol. 2010;53: $671-6$

8. Long XD, Ma Y, Zhou YF, Ma AM, Fu GH. Polymorphism in xeroderma pigmentosum complementation group $\mathrm{C}$ codon 939 and aflatoxin B1-related hepatocellular carcinoma in the Guangxi population. Hepatology. 2010;52:1301-9.

9. Long XD, Ma Y, Qu DY, Liu YG, Huang ZQ, Huang YZ, et al. The polymorphism of XRCC3 codon 241 and AFB1-related hepatocellular carcinoma in Guangxi population, China. Ann Epidemiol. 2008:18:572-8

10. Long XD, Ma Y, Zhou YF, Yao JG, Ban FZ, Huang YZ, et al. XPD codon 312 and 751 polymorphisms, and AFB1 exposure, and hepatocellular carcinoma risk. BMC Cancer. 2009;9:400.

11. Kensler TW, Egner PA, Wang JB, Zhu YR, Zhang BC, Lu PX, et al. Chemoprevention of hepatocellular carcinoma in aflatoxin endemic areas. Gastroenterology. 2004;127:S310-8.

12. Burg WA, Shotwell OL, Saltzman BE. Measurements of airborne aflatoxins during the handling of contaminated corn. Am Ind Hyg Assoc J. 1981;42:1-11.

13. Hamid AS, Tesfamariam IG, Zhang Y, Zhang ZG. Aflatoxin B1induced hepatocellular carcinoma in developing countries: geographical distribution, mechanism of action and prevention. Oncol Lett. 2013;5:1087-92.

14. Sun G, Wang S, Hu X, Su J, Zhang Y, Xie Y, et al. Co-contamination of aflatoxin B1 and fumonisin B1 in food and human dietary exposure in three areas of China. Food Addit Contam Part A Chem Anal Control Expo Risk Assess. 2011;28:461-70.

15. Asim M, Sarma MP, Thayumanavan L, Kar P. Role of aflatoxin B1 as a risk for primary liver cancer in north Indian population. Clin Biochem. 2011;44:1235-40.

16. Anitha S, Raghunadharao D, Waliyar F, Sudini H, Parveen M, Rao R, et al. The association between exposure to aflatoxin, mutation in TP53, infection with hepatitis B virus, and occurrence of liver disease in a selected population in Hyderabad, India. Mutat Res. 2014;766: 23-8.

17. Autrup JL, Schmidt J, Seremet T, Autrup H. Determination of exposure to aflatoxins among Danish workers in animal-feed production through the analysis of aflatoxin B1 adducts to serum albumin. Scand J Work Environ Health. 1991;17:436-40.

18. Autrup JL, Schmidt J, Autrup H. Exposure to aflatoxin B1 in animalfeed production plant workers. Environ Health Perspect. 1993;99: 195-7.

19. Desai MR, Ghosh S. Occupational exposure to airborne fungi among rice mill workers with special reference to aflatoxin producing A. flavus strains. Ann Agric Environ Med. 2003;10:159-62.

20. Abd-Elaah GA, Soliman AS. Occurrence of fungal species and mycotoxins from decayed sugarcane (Saccharrum officinarum) in Egypt. Mycobiology. 2005;33:77-83.

21. Viegas S, Faisca VM, Dias H, Clerigo A, Carolino E, Viegas C. Occupational exposure to poultry dust and effects on the respiratory system in workers. J Toxicol Environ Health A. 2013;76: $230-9$.

22. Ghosh SK, Desai MR, Pandya GL, Venkaiah K. Airborne aflatoxin in the grain processing industries in India. Am Ind Hyg Assoc J. 1997;58:583-6.

23. Zhu LR, Thomas PE, Lu G, Reuhl KR, Yang GY, Wang LD, et al. CYP2A13 in human respiratory tissues and lung cancers: an immunohistochemical study with a new peptide-specific antibody. Drug Metab Dispos. 2006;34:1672-6.

24. Zhang Z, Yang X, Wang Y, Wang X, Lu H, Zhang X, et al. Cytochrome P450 2A13 is an efficient enzyme in metabolic activation of aflatoxin G1 in human bronchial epithelial cells. Arch Toxicol. 2013;87:1697-707.

25. Zhang Z, Lu H, Huan F, Meghan C, Yang X, Wang Y, et al. Cytochrome P450 2A13 mediates the neoplastic transformation of human bronchial epithelial cells at a low concentration of aflatoxin B1. Int J Cancer. 2014;134:1539-48.

26. Van Vleet TR, Klein PJ, Coulombe RJ. Metabolism and cytotoxicity of aflatoxin B1 in cytochrome P-450-expressing human lung cells. J Toxicol Environ Health A. 2002;65:85367.

27. Egner PA, Wang JB, Zhu YR, Zhang BC, Wu Y, Zhang QN, et al. Chlorophyllin intervention reduces aflatoxin-DNA adducts in individuals at high risk for liver cancer. Proc Natl Acad Sci U S A. 2001;98:14601-6.

28. Hu T, Du Q, Ren F, Liang S, Lin D, Li J, et al. Spatial analysis of the home addresses of hospital patients with hepatitis B infection or hepatoma in Shenzhen, China from 2010 to 2012. Int J Environ Res Public Health. 2014;11:3143-55.

29. Wu HC, Santella R. The role of aflatoxins in hepatocellular carcinoma. Hepat Mon. 2012;12:e7238.

30. Qian G, Tang L, Wang F, Guo X, Massey ME, Williams JH, et al. Physiologically based toxicokinetics of serum aflatoxin B1-lysine adduct in F344 rats. Toxicology. 2013;303:147-51.

31. Egner PA, Gange SJ, Dolan PM, Groopman JD, Munoz A, Kensler TW. Levels of aflatoxin-albumin biomarkers in rat plasma are modulated by both long-term and transient interventions with oltipraz. Carcinogenesis. 1995;16:1769-73.

32. Bechtel DH. Molecular dosimetry of hepatic aflatoxin B1-DNA adducts: linear correlation with hepatic cancer risk. Regul Toxicol Pharmacol. 1989;10:74-81. 
33. Tang L, Tang M, Xu L, Luo H, Huang T, Yu J, et al. Modulation of aflatoxin biomarkers in human blood and urine by green tea polyphenols intervention. Carcinogenesis. 2008;29:411-7.
34. Qin G, Ning Y, Lotlikar PD. Chemoprevention of aflatoxin B1initiated and carbon tetrachloride-promoted hepatocarcinogenesis in the rat by green tea. Nutr Cancer. 2000;38:215-22. 